\title{
The study of floral activities and flowering calendar of some selected plant taxa in Akoko environment, Ondo State, Nigeria
}

\author{
Essien Benjamin Christopher * \\ Department of Plant Science and Biotechnology, Faculty of Science, Adekunle Ajasin University, Akungba-Akoko, Ondo \\ State, Nigeria.
}

Publication history: Received on 16 June 2020; revised on 15 July 2020; accepted on 18 July 2020

Article DOI: https://doi.org/10.30574/gscarr.2020.4.1.0056

\begin{abstract}
The patterns of phenological events of an area are variously used for characterization of the vegetation type. Phenological study has great significance because it does not only provide information about the plant growth pattern but it also provides an idea, baseline information and data on the effect of environment and selective pressure on flowering and fruiting behaviour among others. The determination of the floral activities of the flora present in the study environment was carried out using normal random distribution technique and results showed that fourty (40) plant taxa of the vegetation were sampled for various flowering periods in a calendar year and based on their flowering pattern, were placed into five main groups: those that flowered just once, twice, thrice, more than thrice in a calendar year and those that flower nearly all year round. Three (3) species were found to flower once; seven (7) species flower twice; three (3) species flower thrice; twenty-five (25) species flower more than thrice in a calendar year and the other two (2) species flowers nearly all year round. Most flowering activities were recorded in the months of January, February and March whereas the months of August, September and October recorded least flowering activities. Most interestingly, the flowering activities were recorded in all the twelve (12) months in a year calendar. Study provides knowledge about the plants flowering calendar and also gives an insight on the effect of environmental conditions with selective pressure on flowering affecting the behaviour of the plants species thus showing how food is produced throughout the year in the area.
\end{abstract}

Keywords: Phenological; Floral activities; Flowering calendar; Akoko environment; Nigeria

\section{Introduction}

The species composition of vegetation; their periodic stratification and life span are some of the analytical aspect of a plant community. The vegetation of an area is an integral and basic component of the ecosystem and is sensitive to changes in the ecosystem. Consequently, vegetation changes are themselves a response to and a reflection of variation in one or more of the factors of the environment, particularly climate. According to Sowunmi [1], a close relationship exists between vegetation and the rest of the environment, particularly climate and soil. Thus, the flora of an area provides a good reflection of the major climatic regime of the area. The influence of climate on other components of the environment is so great that every other climatic zone has its own characteristic vegetation type.

Phenology is the calendar of events in the life history of plant. It is the scientific study of seasonal change i.e. the periodic phenomena of plants in relation to changes in season and climate. Seasonal and climatic changes are some of the nonliving or abiotic components of the environment that impact the living or biotic components. Phenology is the study of relationship between climatic factors and periodic phenomena in organisms. Pattern of phenological events are variously used for characterization of vegetation type [2].

\footnotetext{
* Corresponding author: Essien Benjamin Christopher
} 
The flowering phenology of plants has been associated with the variability of pollen types in the atmosphere [3]. During the periods of anthesis when plants are in flower, large quantities of pollen grains are discharged into the atmosphere. Consequently, pollen grains that trigger allergic reactions are often specific to a local region where the pollen-producing plants are dominant or exist. This makes it very easy and important to identify allergy-causing pollen grains from each local region [4].

The initiation of growth in plants and changes in phenology are governed by various environmental factors and the influence of temperature and moisture has been widely reported [5]. Hamann [6] suggested that climatic factors are not directly responsible for triggering and synchronization of phenological events.

Progress made in the field of phenology of tropical tree species is encouraging [7 - 9]. In India, the phenology of tree species has been studied in the subtropical forests in north-eastern region [10 - 11] and in western Himalayas [12 - 13]. However, a few attempts have been made to evaluate the phenology of tree species in the tropical dry deciduous forests $[14-15]$.

The study of plant phenology provides knowledge about the pattern of plant growth and development as well as the effects of environment and selective pressures on flowering and fruiting behaviour [16]. Singh and Kushwaha [17] suggested that climate change forced deviations in the length of growing period and competition among species may change the resource use patterns in different species. Karmer [18] reported that differences in tree species phonological responses to temperature changes can have long-term consequences on their geographic distribution. He further suggests that phenology and climate relationship can also reveal the potential impacts of future climate changes.

The timing of sexual reproduction is a critically important determinant of plant reproductive success. Flowering at the optimum time ensures fecundity and good development of seeds and fruits. Flowering phenology is mediated by the interaction of internal factors with external environmental signals such as temperature, day length or drought. In general, plant species in their native ranges have coupled the sensitive flowering period to the optimal climatic conditions through natural selection, thus maximizing their reproductive success. The main selective factors acting upon flowering phenology differ between ecosystems. In Mediterranean-type ecosystems (MTEs), which occur in five widely separated regions of the world, summer drought and rainfall variability modulate the flowering plant response. Drought is one of the most limiting factors for vegetative growth and flower development [7].

Rainfall variability plays an important role in the start and length of flowering phenology in these ecosystems. In less predictable regimes, there is selection for a largely plastic response of start of flowering in order to cope with the uncertain moisture conditions of spring; this also occurs in other seasonally dry ecosystems [6]. Climate-change studies focused on responses of wide-ranging plant species occurring along latitudinal gradients corroborate the idea of high phenological plasticity in fluctuating environments.

Widespread introductions of plant species to areas outside their natural ranges provide the opportunity to gain new insights into the importance of flowering phenology as a component of success of alien species in a new region, since enhanced fecundity appears to be an important trait associated with invasiveness. To be a successful invader, introduced plants must first cope with the abiotic filters imposed by the new region and then reproduce. This requires them to flower at the appropriate time of the year, which will depend on the plant's requirements [19].

Flowering phenology has been shown to be fairly flexible in within-alien comparisons. For example, successful invaders generally display early flowering or long blooming period, since the chance of acquiring improved fitness via effective pollination visits is increased. On the other hand, late, short flowering gives insufficient time for completion of the life cycle or results in a shorter time for pollination, reducing opportunities for fruit and seed development. In the case of alien-native comparisons, many authors have found that invasive alien species flower earlier than natives [20]. Others have found that alien species that flower later than natives are more abundant. Exhibiting a different flowering pattern compared with native species may be more frequent in those alien species which have evolved under climatic conditions markedly different from those of the invaded region. This premise is based on the following argument: if plant species maintain their genetic inertia of timing of flowering when they are introduced in a new ecosystem, different flowering phenology between invasive and native species may occur as a direct result of different strategies of reproduction selected by evolution. On the other hand, invasive species with the same climatic conditions in their native and invaded ecosystems will not show any difference in flowering phenology [17].

West tropical Africa (WTA) is known to be one of the most exposed regions in the world to climate change. The seasonality of rainfall and of atmospheric conditions, including a dry season lasting for several months in most of the area, strongly influences vegetation activity [21]. Indeed, this region was already affected by severe and prolonged 
droughts in the 1970s-1980s. These events represent one of the major climate variations of the 20th century recorded at the global scale [22]. In WTA, the current vulnerability of agro- and eco-systems to climate change is dramatically amplified by the rapidly growing population [21].

The phenology of woody plants could be thus a significant indicator of the vulnerability and ability of existing agrosylvo-pastoral ecosystems to respond to local and global changes through their relationships with regional climate, soil distribution and land use [23]. On the other hand, changes in the woody cover may also interact with the effect of global change on ecosystems through changes in leaf phenology (variations in the leaf area index). The relationships between environmental conditions and woody plant phenology are still poorly known, notably in seasonally dry tropics [24].

The first phenological studies in the humid part of the gradient were conducted in the 1960s and mainly concerned leaf shedding and increments of the stand basal area, especially in forests. Studies in the driest part of the gradient were mainly classical qualitative characterization of leafing, flowering and fruiting at the population scale. However, the most recent studies conducted in Sahelian and Sudanian bioclimates included quantitative data analyses and modelling and made a thorough study of the most probable determining factors of phenology. Most studies were conducted along a transect from Guinean to Sahelian areas, and focused on the description of specific phenological strategies. Studies on this topic and long-time series of phenological data are particularly rare in WTA. The aim of this study was to determine the floral activities and the phenological phases/pattern of the flora present in the vegetation of the study area over the year.

\section{Material and methods}

\subsection{Determination of floral activities}

A normal random distribution technique was used to mark out 2-hectares of plot. Fourty (40) stands of each plant taxa identified were tagged with a ribbon-material. The two plots were visited twice in a month (i.e. first week and last week of every month). The floral activities (i.e. when there is any initiation of flowering on any of the 40 tagged stands were recorded as a positive sign ( + ) and if non-flowering it was recorded as negative (-) sign within the column) according to the methods of Usman [25] and Hemen [26]. This exercise was repeated the following year to confirm the observation in the first year.

\subsection{Preparation of pollen samples and slides}

Fresh pollen samples were collected from the flowers of the flowering species. Anthers from both flower buds and the already open flowers were carefully removed with a piercing needle and a pair of forceps and crushed in a beaker containing ethanol (alcohol). These were sieved, centrifuged at 2500 r.p.m. (revolution per minute) for 5 minutes and decanted. The pollen sediments were treated with glacial acetic acid to remove water before acetolysis. Acetolysis was carried out by boiling the sediments in a water bath at $100^{\circ} \mathrm{C}$ according to the methods of [27 - 29]. The recovered precipitates were washed with glacial acetic acid, and finally washed twice with distilled water, centrifuged each time and decanted. The recovered pollen sediments were stored in a plastic vials in glycerin and ethanol solution (2:1).

One drop of thoroughly shaken precipitates solution was mounted on microscope slides and covered with $18 \times 18 \mathrm{~mm}$ cover slip. The mount was sealed off with colourless nail vanish to prevent drying up of the mount. The prepared slides were then examined microscopically with Olympus microscope at x400 magnification for counting and Leica microscope at x1000 magnification for detailed morphological studies. Pollen identification, morphological examination and analysis were done with the help of reference descriptions and photomicrographs from Bonnefille and Riollet [30], Sowunmi [31] and Shubharani et al. [32]. In addition, prepared slides of pollen samples in the Palynological Research Unit; Department of Plant Science and Biotechnology, Adekunle Ajasin University, Akungba- Akoko, Nigeria were used.

\section{Results and discussion}

The patterns of phonological events of an area are variously used for characterization of the vegetation type of that area. Fourty (40) plant taxa of the vegetation were sampled for various flowering periods in a calendar year and based on their flowering pattern were placed into five main groups: those that flowered just once, twice, thrice, more than thrice in a calendar year and those that flower nearly all year round.

The results in Tables 1 have shown the floral pattern of the species of the study area. Fourty (40) plant species of the vegetation were sampled during the study and their numbers of flowering period in a year were recorded. Three (3) species: Alstonia boonei, Annona senegalensis and Milicia excelsa were found to flower once; Seven (7) species: Bombax 
buonopozense, Brachystegia eurycoma, Khaya senegalensis, Lophira alata, Prosopis africana, Tectona grandis and Vitex grandifolia were found to flower twice; three (3) species: Cnestis ferruginea, Nauclea latifolia (Sarcocephalus litifolius) and Senna occidentale were found to flower thrice; twenty-five (25) species were found to flower more than thrice in a calendar year and the other two (2) species: Elaeis guineensis and Poaceae flowers nearly all year round (Table 2). Most flowering activities were recorded in the months of January, February and March. Meanwhile, the months of August, September and October have recorded least flowering activities during the study (Table 1). Most interestingly, the flowering activities were recorded in all the twelve (12) months in a year calendar (Table 1). Thus, it is one of the main features of biological (ecological) interest of the vegetation. Photomicrographs of some selected pollen types of these plant taxa are presented in Fig. 1.
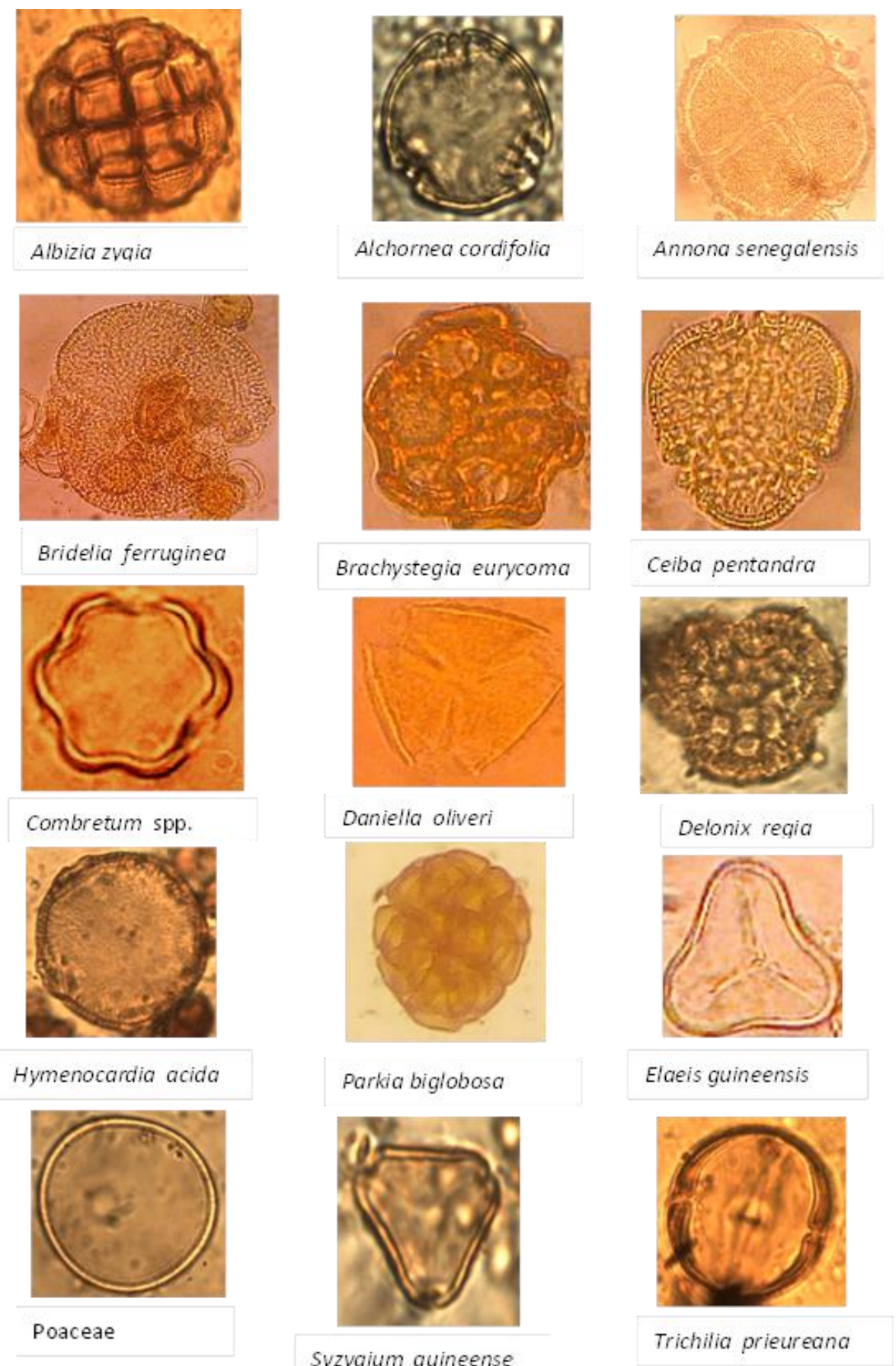

Figure 1 Photomicrographs of some selected pollen types recorded in the study. SOURCE: After Essien, 2019 
Table 1 Flowering Calendar of some selected plant taxa in Akoko Environmen

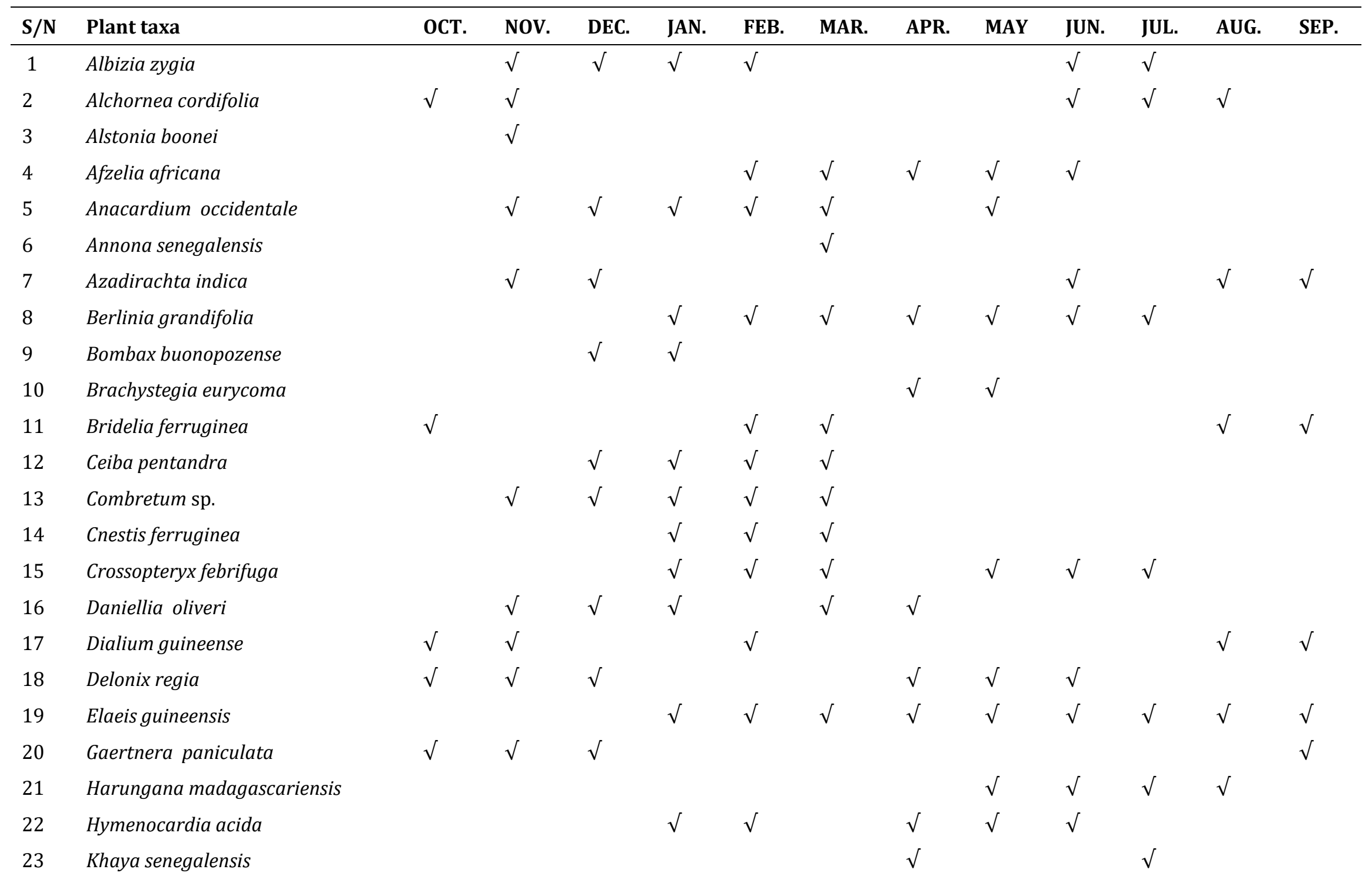


Essien / GSC Advanced Research and Reviews, 2020, 04(01), 059-068

\begin{tabular}{|c|c|c|c|c|c|c|c|c|c|c|c|c|c|}
\hline $\mathrm{S} / \mathrm{N}$ & Plant taxa & OCT. & NOV. & DEC. & JAN. & FEB. & MAR. & APR. & MAY & JUN. & JUL. & AUG. & SEP. \\
\hline 24 & Kigelia africana & $\sqrt{ }$ & & & & & & & $\sqrt{ }$ & $\sqrt{ }$ & $\sqrt{ }$ & $\sqrt{ }$ & $\sqrt{ }$ \\
\hline 25 & Lannea acida & & & & $\sqrt{ }$ & $\sqrt{ }$ & $\sqrt{ }$ & $\sqrt{ }$ & & & & & \\
\hline 26 & Lophira alata & & $\sqrt{ }$ & $\sqrt{ }$ & & & & & & & & & \\
\hline 27 & Milicia excelsa & & & $\sqrt{ }$ & & & & & & & & & \\
\hline 28 & Nauclea latifolia & & & & & & & & $\sqrt{ }$ & $\sqrt{ }$ & $\sqrt{ }$ & & \\
\hline 29 & Parkia biglobosa & & & $\sqrt{ }$ & $\sqrt{ }$ & $\sqrt{ }$ & & $\sqrt{ }$ & $\sqrt{ }$ & $\sqrt{ }$ & & & \\
\hline 30 & Parinari curatellifolia & & & $\sqrt{ }$ & $\sqrt{ }$ & $\sqrt{ }$ & $\sqrt{ }$ & $\sqrt{ }$ & & & & & \\
\hline 31 & Pentaclethra macrophylla & $\sqrt{ }$ & $\sqrt{ }$ & $\sqrt{ }$ & $\sqrt{ }$ & $\sqrt{ }$ & $\sqrt{ }$ & $\sqrt{ }$ & $\sqrt{ }$ & & $\sqrt{ }$ & $\sqrt{ }$ & $\sqrt{ }$ \\
\hline 32 & Phyllanthus sp. & $\sqrt{ }$ & & & $\sqrt{ }$ & $\sqrt{ }$ & $\sqrt{ }$ & $\sqrt{ }$ & $\sqrt{ }$ & $\sqrt{ }$ & $\sqrt{ }$ & $\sqrt{ }$ & $\sqrt{ }$ \\
\hline 33 & Piliostigma thonningii & & & $\sqrt{ }$ & & & & & & & $\sqrt{ }$ & $\sqrt{ }$ & $\sqrt{ }$ \\
\hline 34 & Poaceae & $\sqrt{ }$ & $\sqrt{ }$ & $\sqrt{ }$ & $\sqrt{ }$ & $\sqrt{ }$ & $\sqrt{ }$ & $\sqrt{ }$ & $\sqrt{ }$ & $\sqrt{ }$ & $\sqrt{ }$ & $\sqrt{ }$ & $\sqrt{ }$ \\
\hline 35 & Prosopis africana & & & $\sqrt{ }$ & $\sqrt{ }$ & & & & & & & & \\
\hline 36 & Senna occidentalis & & & & & & & & $\sqrt{ }$ & $\sqrt{ }$ & $\sqrt{ }$ & & \\
\hline 37 & Syzygium guineense & & $\sqrt{ }$ & $\sqrt{ }$ & $\sqrt{ }$ & $\sqrt{ }$ & $\sqrt{ }$ & $\sqrt{ }$ & $\sqrt{ }$ & & & & \\
\hline 38 & Tectona grandis & & & & & & & & & $\sqrt{ }$ & $\sqrt{ }$ & & \\
\hline 39 & Trichilia prieureana & & & & $\sqrt{ }$ & $\sqrt{ }$ & $\sqrt{ }$ & $\sqrt{ }$ & & & & & \\
\hline 40 & Vitex grandifolia & & & & & & $\sqrt{ }$ & & $\sqrt{ }$ & & & & \\
\hline
\end{tabular}

Note: The tick $(\sqrt{ })$ means the flowering period. 
Similar findings were reported by Borchert [7] who opined that plant taxa flowering at their optimum time may ensure fecundity and good development of their seeds and fruits. This flowering pattern of the vegetation is seen to be mediated by the interaction of internal factors with external environmental signals such as optimum climatic conditions. The variations in flowering periods among the plant taxa have shown that each plant taxon has its own optimum time (month) of flowering (Table 2).

Table 2 Phenological Phases (Floral Pattern) of some selected plant taxa in the study are

\begin{tabular}{|c|c|c|}
\hline$S / N$ & Plant taxa & Number of flowering period in a year \\
\hline 1 & Albizia zygia & $>3$ times \\
\hline 2 & Alchornea cordifolia & $>3$ times \\
\hline 3 & Alstonia boonei & 1 \\
\hline 4 & Afzelia africana & $>3$ times \\
\hline 5 & Anacardium occidentale & $>3$ times \\
\hline 6 & Annona senegalensis & 1 \\
\hline 7 & Azadirachta indica & $>3$ times \\
\hline 8 & Berlinia grandifolia & $>3$ times \\
\hline 9 & Bombax buonopozense & 2 \\
\hline 10 & Brachystegia eurycoma & 2 \\
\hline 11 & Bridelia ferruginea & $>3$ times \\
\hline 12 & Ceiba pentandra & $>3$ times \\
\hline 13 & Combretum sp. & $>3$ times \\
\hline 14 & Cnestis ferruginea & 3 \\
\hline 15 & Crossopteryx febrifuga & $>3$ times \\
\hline 16 & Daniellia oliveri & $>3$ times \\
\hline 17 & Dialium guineense & $>3$ times \\
\hline 18 & Delonix regia & $>3$ times \\
\hline 19 & Elaeis guineensis & All year round \\
\hline 20 & Gaertnera paniculata & $>3$ times \\
\hline 21 & Harungana madagascariensis & $>3$ times \\
\hline 22 & Hymenocardia acida & $>3$ times \\
\hline 23 & Khaya senegalensis & 2 \\
\hline 24 & Kigelia africana & $>3$ times \\
\hline 25 & Lannea acida & $>3$ times \\
\hline 26 & Lophira alata & 2 \\
\hline 27 & Milicia excelsa & 1 \\
\hline 28 & Nauclea latifolia & 3 \\
\hline 29 & Parkia biglobosa & $>3$ times \\
\hline 30 & Parinari curatellifolia & $>3$ times \\
\hline 31 & Pentaclethra macrophylla & $>3$ times \\
\hline 32 & Phyllanthus sp. & $>3$ times \\
\hline 33 & Piliostigma thonningii & $>3$ times \\
\hline 34 & Poaceae & All year round \\
\hline 35 & Prosopis africana & 2 \\
\hline 36 & Senna occidentalis & 3 \\
\hline 37 & Syzygium guineense & $>3$ times \\
\hline 38 & Tectona grandis & 2 \\
\hline 39 & Trichilia prieureana & $>3$ times \\
\hline 40 & Vitex grandifolia & 2 \\
\hline
\end{tabular}


In separate studies, positive relationships have been established between pollen concentration in the atmosphere and the major flowering period of the plants [33 - 35]. With reference to the monthly pollen variability in the atmosphere, the results showed that the concentration of pollen grains in the atmosphere fluctuates considerably with the seasons. The monthly airborne pollen concentrations showed three discernible periods of pollen variability in the atmosphere. The three periods of pollen abundance in the atmosphere showed that the highest mean concentration occurred during the late rainy season to early dry season followed by the period of dry season to early rainy season and the least occurred during the mid-rainy season (Table 3). This also coincides with the flowering period (season) of the species represented by their pollen grains.

Table 3 Season of pollen abundance and variability in the atmosphere

\begin{tabular}{llll}
\hline S/N & Seasons & Months & Pollen counts \\
\hline 1 & Late rainy season to early dry season & September to January & 33,444 \\
2 & Dry season to early rainy season & February to June & 13,761 \\
3 & Mid rainy season & July to August & 3,456 \\
& Cumulative total pollen counts & & 50,661 \\
\hline
\end{tabular}

SOURCE: After Essien and Ige, 2019

Singh and Kushwaha [17] reported that, plants generally in their native range may, couple with sensitive flowering period to the optimum climatic conditions through natural selection, maximize their reproductive success. Rainfall, relative humidity and temperature variability of this area may play an important role in the start and length of the flowering phenology of this ecosystem as similarly reported by Hamann [6] in Mediterranean-type ecosystem.

\section{Conclusion}

Results of this study showed that most of these plants taxa flowers during the period of lesser rainfall (dry season) that is, the months of November to March when the sun shines more brightly and the atmospheric humidity is lower. These climatic conditions are more suitable for the flight of insects (for example bees) and positive pollination ecology. The information obtained during this phenology study has a great significance because it did not only provides knowledge about the plants flowering calendar but also provides an idea on the effect of environmental conditions with selective pressure on flowering affecting the behaviour of the plants species thus showing how food is produced throughout the year in the area.

\section{Compliance with ethical standards}

\section{Acknowledgments}

The author (Dr. Benjamin Christopher Essien) is grateful to God for wisdom, inspiration and resources and to the Acting Vice Chancellor of Adekunle Ajasin University, Akungba-Akoko; Professor Olugbenga E. Ige (Professor of Palynology and Palaeoecology) for his deep interest, scrutiny and painstaking/ invaluable commitment to this research. I appreciate my wife's (Mrs. Glory) support and understanding during my many months of absence from home.

\section{Disclosure of conflict of interest}

The author declares that there is no conflict of interest.

\section{References}

[1] Sowunmi MA. (1987). Palynological studies in the Niger Delta. In: E.J. Alagoa, F.N. Anozie and Nwanna Nzewunwa (Eds.). The early history of the Niger Delta. Helmat Buske Verlag Hamburg, 29-59.

[2] Opler PA, Frankie GW and Baker HG. (1980). Comparative phenological studies of treelet and shrubs species in tropical wet and dry forests in the lowlands of Costa Rica. Journal of Ecology, 68, 167-188.

[3] Essien BC. (2019). The Study of Quaternary Airborne Palynomorphs in Akoko Environment, Ondo State, Nigeria. PhD Thesis, Department of Plant Science and Biotechnology, Adekunle Ajasin University, Akungba- Akoko, Ondo State, Nigeria, 493. 
[4] Ige OE and Essien BC. (2019). The applications of pollen analysis in environmental monitoring in Akoko NorthEast Local Government Area of Ondo State, Nigeria. GSC Biological and Pharmaceutical Sciences, 8 (1), 64-77.

[5] Dewald LE and Steiner KC. (1986). Phenology, height increment and cold tolerance of Alnus glutinosa population in a common environment. Silvae Genetica, 35, 205-211.

[6] Hamann A. (2004). Flowering and fruiting phenology of a Philippine submontane rain forest: climatic factors as proximate and ultimate causes. Journal of Ecology, 92, 24-31.

[7] Borchert R. (1983). Phenology and control of flowering in tropical trees. Biotropica, 15, 81-89.

[8] Croat TB. (1975). Phenological behaviour of habit and habitat classes on Barro Colorado Island (Panama canal zone). Biotropica, 7, 270 - 277.

[9] Sun C, Kaplin BA, Kristensen KA, Munyallgoga AJ, Mvuklyumwami J, Kajonda KK and Moermond TC. (1996). Tree phenology in a tropical montane forest in Rwanda. Biotropica, 28, 668-681.

[10] Boojh R and Ramakrishnan PS. (1981). Phenology of tree in sub-tropical evergreen Monta forest in Northeast India. Geo-Eco-Trop, 5, 189-209.

[11] Kikim A and Yadava PS. (2001). Phenology of tree species in subtropical forests of Manipur in north eastern India. Tropical Ecology, 42, 269-276.

[12] Ralhan PK, Khanna RK, Singh SP and Singh JS. (1985). Phenological characteristics of the tree layer of Kumaun Himalayan forests. Vegetation, 60, 91-101.

[13] Sundriyal RC. (1990). Phenology of some temperate woody species of the Garhwal Himalaya. International Journal of Ecology and Environmental Sciences, 6, 107-117.

[14] Khan JA. (1999). Periodicity of major phenophages in woody species in dry deciduous forests of Gir, India. Tropical Ecology, 40, 299-303.

[15] Kushwaha CP and Singh KP. (2005). Diversity of leaf phenology in a tropical deciduous forest in India. Journal of Tropical Ecology, 21, 47-56.

[16] Zhang G, Song Q and Yang D. (2006). Phenology of Ficus racemosa in Xishuangbanna, Southwest China. Biotropica, 38: 334-341.

[17] Singh KP and Kushwaha CP. (2005). Emerging paradigms of tree phenology in dry tropics. Current Science, 89, 964-975.

[18] Karmer K. (1997). Phenology and growth of European trees in relation to climate change. In: Leith, H. and Schwartz, M.D. (Eds.) Phenology of Seasonal Climates I. Bakhuys, The Netherlands, 50.

[19] Borchert R, Rivera G and Hagnauer W. (2002). Modification of vegetative phenology in a tropical semi-deciduous forest by abnormal drought and rain. Biotropica, 34, 27-39.

[20] Borchert R and Rivera G. (2001). Photoperiodic control of seasonal development and dormancy in tropical stemsucculent trees. Tree Physiology, 21, 213-221.

[21] Tormo R, Silva I, Gonzalo A, Moreso A, Perez R and Fernandez S. (2011). Phenological records as a complement to aerobiological data. International Journal of Biometeorology, 55, 51-65.

[22] Giorgi F. (2002). Variability and trends of sub-continental scale surface climate in the twentieth century. Part I: observations. Climate Dynamics, 18(8), 675-691.

[23] Chuine I and Beaubien EG. (2001). Phenology is a major determinant of tree species range. Ecology Letters, 4(5), 500-510.

[24] Eamus D and Prior L. (2001). Ecophysiology of trees of seasonally dry tropics: comparisons among phenologies. In: Advances in Ecological Research, Vol. 32, Caswell, H. (Ed.). Academic Press-Elsevier, London, 113-197.

[25] Usman SS. (1990). Ecological studies of Opi Lake savanna woodland. Ph.D Thesis, Department of Botany, University of Nigeria, Nsukka, 202p.

[26] Hemen TJ. (2015). Ecological studies of the derived savanna at Egume, Kogi State, Nigeria. Ph.D Thesis, Department of Biological Sciences, Kogi State University, Anyigba, Nigeria, 180.

[27] Erdtman G. (1969). Handbook of Palynology. Muntisguard, Copenhagen, 280 - 285. 
[28] Agwu COC and Akanbi TO. (1985). A palynological study of honey from four vegetation zones of Nigeria. Pollen et Spores, 27, 335-348.

[29] Paul E, Essien BC, Idachaba SO, Edegbo E and Tamenku MM. (2014). Comparative Study of Pollen Morphology of some members of Euphorbiaceae Family. Standard Research Journal of Agricultural Sciences, 2(4), 045- 058.

[30] Bonnefille R and Riollet G. (1980). Pollen des savanna d'Afrique orientale. Anatole Press, Paris, France, 1- 140.

[31] Sowunmi MA. (1995). Pollen of Nigerian plants II. Grana, 34, 120 -141.

[32] Shubharani R, Roopa P and Sivaram V. (2013). Pollen morphology of selected bee forage plants. Global Journal of Bio-Science and Biotechnology, 2(1), 82- 90.

[33] Molina, RT, Palacios IS, Rodriguez, AFM, Munoz JT and Corcheros AM. (2001). Environmental factors affecting airborne pollen concentration in anemophilous species of Plantago. Annals of Botany, 87, 1- 8.

[34] Jato V, Mendez J, Rodriguez-Rajo J and Seijo C. (2002). The relationship between the flowering phenophase and airborne pollen of Betula in Galicia (N.W. Spain). Aerobiologia, 18, 55-64.

[35] Njokuocha RC. (2006). Airborne pollen grains in Nsukka, Nigeria. Grana, 45, 73-80.

\section{How to cite this article}

Essien BC. (2020). The study of floral activities and flowering calendar of some selected plant taxa in Akoko environment, Ondo State, Nigeria. GSC Advanced Research and Reviews, 4(1), 59-68. 